\title{
Component Misassembled
}

National Cancer Institute

\section{Source}

National Cancer Institute. Component Misassembled. NCI Thesaurus. Code C133498.

A device is found to have one or more components incorrectly assembled when delivered to the user facility. 